\title{
Cornelia de Lange Syndrome: A Newborn with Imperforate Anus and a NIPBL Mutation
}

\author{
Rose H. Mende, ${ }^{1,2}$ David P. Drake, ${ }^{3}$ Raimos M. Olomi, ${ }^{1,2}$ and Ben C. J. Hamel ${ }^{4}$ \\ ${ }^{1}$ Department of Paediatrics and Child Health, Kilimanjaro Christian Medical Centre, P.O. Box 2240, Moshi, Tanzania \\ ${ }^{2}$ Department of Paediatrics and Child Health, Kilimanjaro Christian Medical University College, P.O. Box 2240, Moshi, Tanzania \\ ${ }^{3}$ Department of Paediatric Surgery, Hospital for Sick Children, Great Ormond Street, London WC1N 3JH, UK \\ ${ }^{4}$ Directorate of Postgraduate Studies, Kilimanjaro Christian Medical University College, P.O. Box 2240, Moshi, Tanzania
}

Correspondence should be addressed to Ben C. J. Hamel, b.hamel1503@gmail.com

Received 30 October 2012; Accepted 21 November 2012

Academic Editors: P. Morrison and M. Suri

Copyright ( $) 2012$ Rose H. Mende et al. This is an open access article distributed under the Creative Commons Attribution License, which permits unrestricted use, distribution, and reproduction in any medium, provided the original work is properly cited.

Cornelia de Lange syndrome is a dominantly inherited, genetically heterogeneous and clinically variable syndrome with multiple congenital anomalies and developmental delay. Gastrointestinal anomalies are common and an important cause of morbidity and mortality. We report on a newborn with a molecularly confirmed Cornelia de Lange syndrome who had an imperforate anus. This is the third report of Cornelia de Lange syndrome and imperforate anus.

\section{Introduction}

Cornelia de Lange syndrome (CdLs) (OMIM no. 122470, 300590, and 610759) is a well-known, dominantly inherited, variable syndrome with multiple congenital anomalies and developmental delay. It is a mainly characterized by craniofacial, limb and growth anomalies, and motor and intellectual disability. A variety of other anomalies (gastrointestinal, cardiac, renal, genital, and ocular) are often also present. Prevalence is estimated to be as high as $1 / 10,000$ [1]. In a classical case, clinically, the diagnosis is not difficult, but in mild cases it might be more challenging. CdLs is genetically heterogeneous. In more than $50 \%$ of cases, a heterozygous, mostly de novo, mutation can be detected in one of 3 cohesin structural components encoding genes NIPBL $(5 \mathrm{p} ; \sim 50 \%)$, SMC1A (10q; $\sim 5 \%$ ) and SMC3 (Xp; <1\%; hemizygous), while recently mutations in a 4 th related gene, HDAC8 (Xq), were identified (OMIM no. 300882) [2]. In a further related gene, RAD21 (8q) mutations were found in a mild CdLs phenotype (OMIM no. 614701) [3].

A number of CdLs reviews, highlighting clinical features and genotype-phenotype correlations, are available in the literature [4-9].

We report a case with an imperforate anus, in whom a NIPBL mutation was detected.

\section{Case Report}

A one-day-old male newborn was referred to our hospital due to an imperforate anus. He was born vaginally after an uneventful pregnancy, apparently full term, with a birth weight of $1800 \mathrm{gr}$ and an OFC of $29 \mathrm{~cm}$, both far below the 2nd percentile. His nonconsanguineous parents are healthy as are his 5 siblings. Dysmorphic features were immediately noted: hirsute forehead, synophrys, bushy and arched eyebrows, long eyelashes, depressed nasal bridge, thin upper lip with down-turned corners, long philtrum, and micrognathia (Figure 1). Furthermore, generalized hirsutism was seen (Figure 2), as well as clinodactyly of the left fifth finger (Figure 3), limited elbow extension, and coronal hypospadias. The imperforate anus was confirmed. He had a weak sucking reflux and a weak cry.

Chest X-ray and echocardiography were normal. Abdominal ultrasound revealed moderate right-sided hydronephrosis, while the left kidney could not be visualized.

A colostomy was performed. He was discharged in a fair condition after 2 weeks and regular followup was initiated.

Venous blood was sampled, and DNA was sent to the Netherlands (DNA Diagnostic Laboratory, Department of Clinical Genetics, Amsterdam Medical Centre, Amsterdam). Sequence analysis of the NIPBL gene revealed a heterozygous 


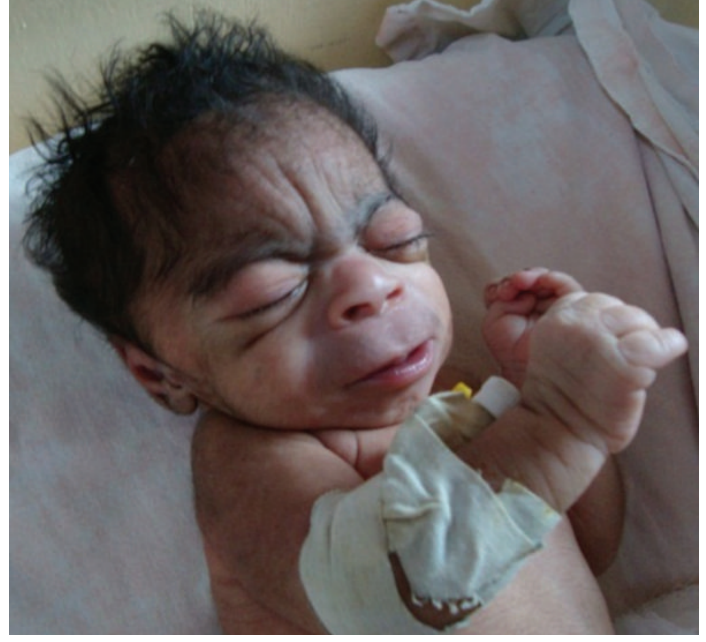

FIgURE 1: The characteristic craniofacial features of Cornelia de Lange syndrome.

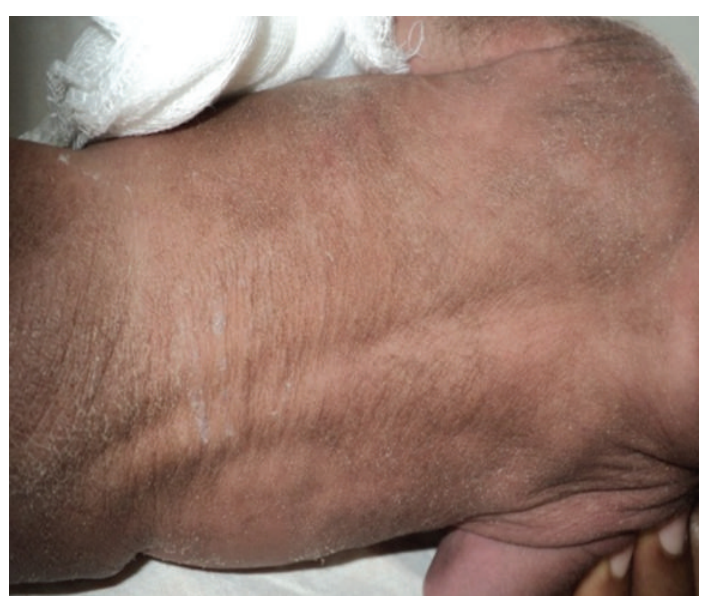

FIGURE 2: Generalized hirsutism.

nonsense mutation (c.3445C $>\mathrm{T}$ ), leading to a premature stop codon in the protein (p.Arg1149X), thereby confirming the clinical diagnosis of CdLs.

\section{Discussion}

Due to the presence of the classical craniofacial features and prenatal growth retardation, there was a little doubt that CdLs was the correct diagnosis, though the limb anomalies were mild. The nonsense mutation in the NIPBL gene leading to a truncated protein confirmed the diagnosis. Though DNA of the healthy parents was not analysed, it is reasonable to assume that the mutation occurred de novo, though germline mosaicism cannot be excluded. The c.3445C $>\mathrm{T}$ mutation has not been described before. However, the great majority of NIPBL mutations found so far are private mutations, while a small minority are recurrent mutations $[5,6,8]$.

Gastrointestinal anomalies are frequent in CdLs and an important cause of morbidity and mortality [9, 10]. The

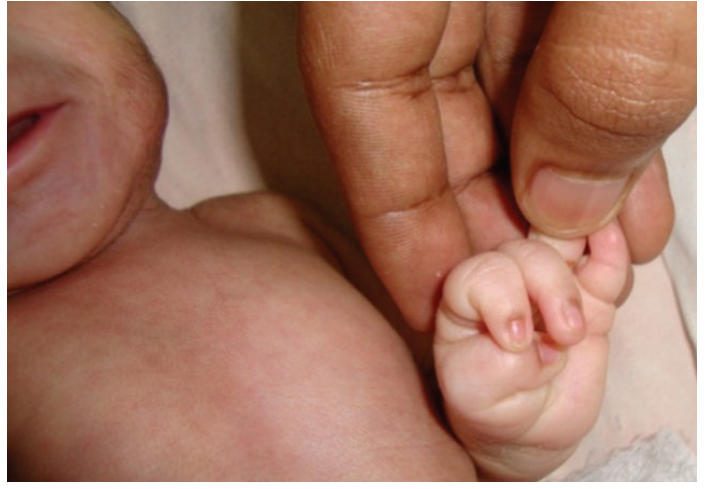

Figure 3: Clinodactyly of left fifth finger.

commonest is gastrooesophageal reflux with its sequelae [11]. Less frequent among others are pyloric stenosis, malrotation with volvulus, congenital diaphragmatic hernia, and small bowel duplication. Though hundreds of cases of CdLs have been described, to our knowledge, imperforate anus has only been reported twice: one in a Korean case and one in an overview of causes of mortality in CdLs $[9,12]$.

In conclusion, imperforate anus is an infrequent feature of CdLs, which should be added to the list of CdLs features in databases and textbooks.

\section{Acknowledgments}

The authors gratefully acknowledge the help of Drs. Redeker and Alders, clinical molecular geneticists of the DNA Diagnostic Laboratory, Department of Clinical Genetics, Amsterdam Medical Centre, Amsterdam, The Netherlands, who performed the NIPBL sequence analysis free of charge.

\section{References}

[1] J. M. Opitz, "Editorial comment: The Brachmann-de Lange syndrome," American Journal of Medical Genetics, vol. 22, no. 1, pp. 89-102, 1985.

[2] M. A. Deardorff, M. Bando, R. Nakato et al., "HDAC8 mutations in Cornelia de Lange syndrome affect the cohesin acetylation cycle," Nature, vol. 489, no. 7415, pp. 313-317, 2012.

[3] M. A. Deardorff, J. J. Wilde, M. Albrecht et al., "RAD21 mutations cause a human cohesinopathy," American Journal of Human Genetics, vol. 90, no. 6, pp. 1014-1027, 2012.

[4] L. Jackson, A. D. Kline, M. A. Barr, and S. Koch, "de Lange syndrome: A clinical review of 310 individuals," American Journal of Medical Genetics, vol. 47, no. 7, pp. 940-946, 1993.

[5] L. A. Gillis, J. McCallum, M. Kaur et al., "NIPBL mutational analysis in 120 individuals with Cornelia de Lange syndrome and evaluation of genotype-phenotype correlations," American Journal of Human Genetics, vol. 75, no. 4, pp. 610-623, 2004.

[6] Z. A. Bhuiyan, M. Klein, P. Hammond et al., "Genotypephenotype correlations of 39 patients with Cornelia de Lange syndrome: The Dutch experience," Journal of Medical Genetics, vol. 43, no. 7, pp. 568-575, 2006.

[7] A. D. Kline, I. D. Krantz, A. Sommer et al., "Cornelia de Lange syndrome: Clinical review, diagnostic and scoring systems, 
and anticipatory guidance," American Journal of Medical Genetics, Part A, vol. 143, no. 12, pp. 1287-1296, 2007.

[8] C. Oliver, M. F. Bedeschi, N. Blagowidow et al., "Cornelia de Lange syndrome: Extending the physical and psychological phenotype," American Journal of Medical Genetics, Part A, vol. 152, no. 5, pp. 1127-1135, 2010.

[9] S. A. Schrier, I. Sherer, M. A. Deardorff et al., "Causes of death and autopsy findings in a large study cohort of individuals with Cornelia de Lange syndrome and review of the literature," American Journal of Medical Genetics, Part A, vol. 155, no. 12, pp. 3007-3024, 2011.

[10] M. J. Bull, J. F. Fitzgerald, S. A. Heifetz, and T. J. Brei, "Gastrointestinal abnormalities: A significant cause of feeding difficulties and failure to thrive in Brachmann-de Lange syndrome," American Journal of Medical Genetics, vol. 47, no. 7, pp. 1029-1034, 1993.

[11] S. Luzzani, F. Macchini, A. Valadè, D. Milani, and A. Selicorni, "Gastroesophageal reflux and Cornelia de Lange syndrome: Typical and atypical symptoms," American Journal of Medical Genetics, vol. 119, no. 3, pp. 283-287, 2003.

[12] S. H. Lee, J. W. Jang, I. S. Kim, W. D. Kim, and S. G. Lee, "A case of Cornelia de Lange syndrome with imperforate anus," Journal of the Korean Society of Neonatology, vol. 14, pp. 253$257,2007$. 


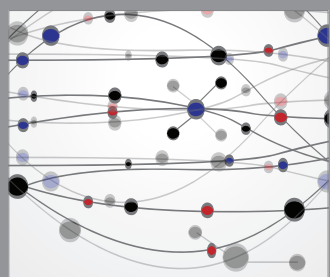

The Scientific World Journal
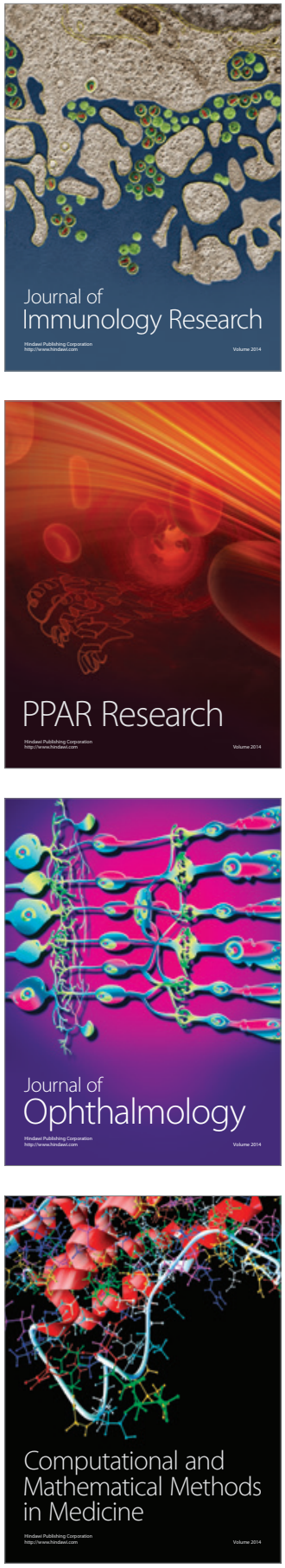

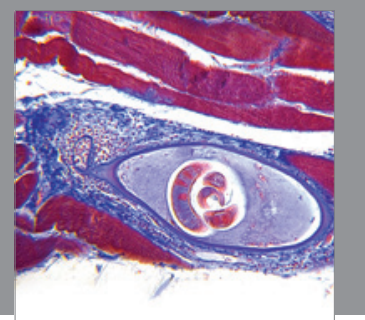

Gastroenterology

Research and Practice
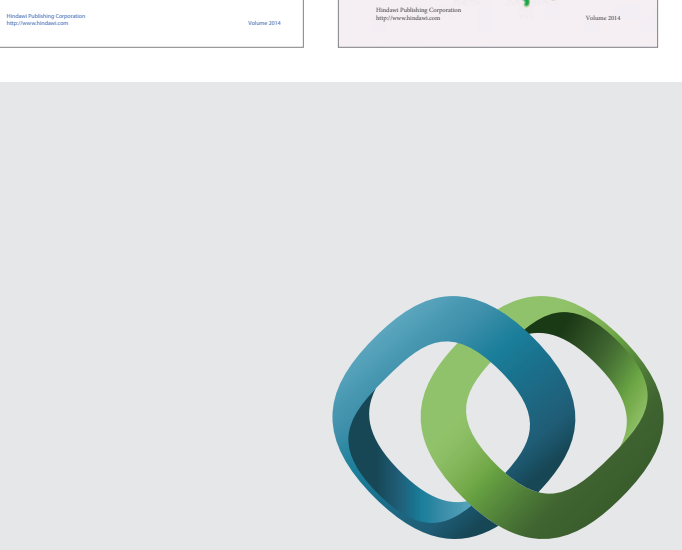

\section{Hindawi}

Submit your manuscripts at

http://www.hindawi.com
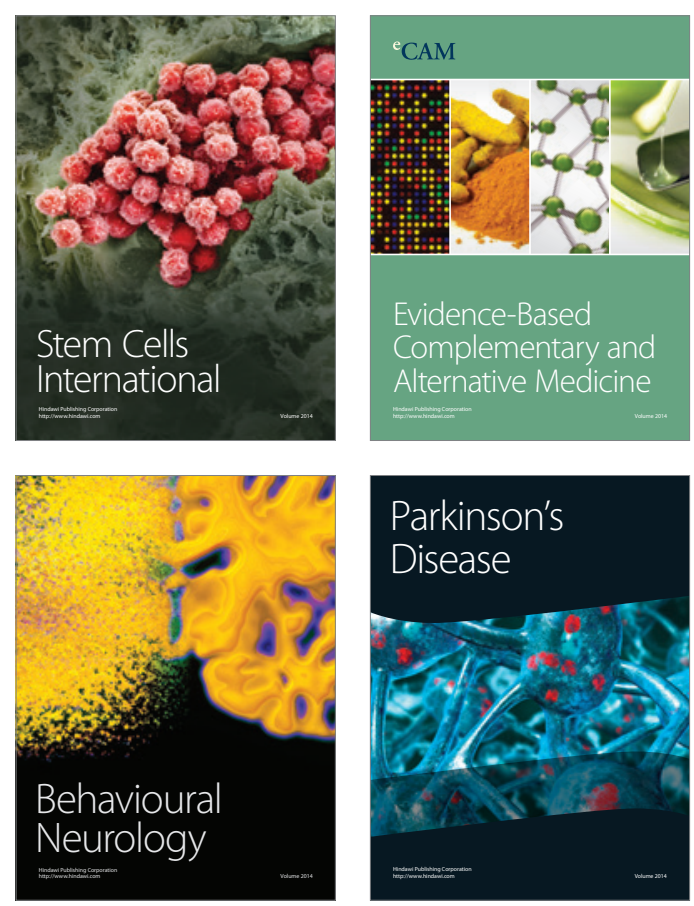

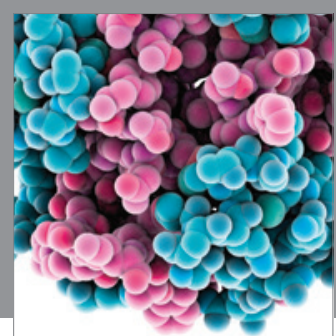

Journal of
Diabetes Research

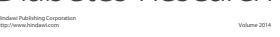

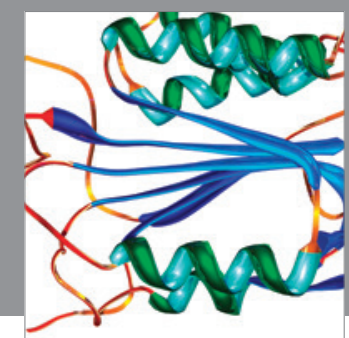

Disease Markers
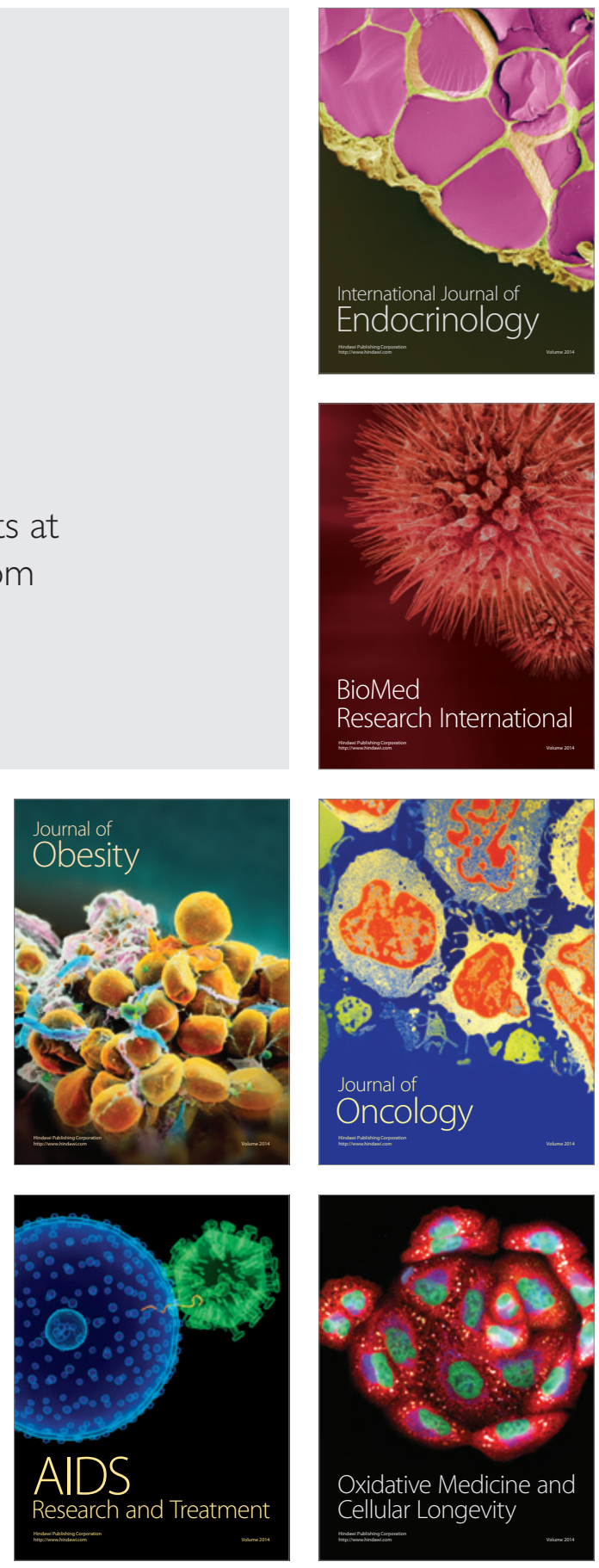